\title{
Teknik dan Metode Penerjemahan Kalimat Imperatif dalam Novel Girls in The Dark oleh Andry Setiawan
}

\author{
Nadya Rizkiana Madjid ${ }^{1)}$, Ni Made Andry Anita Dewi ${ }^{2)}$, Ngurah Indra Pradhana ${ }^{3)}$ \\ ${ }^{[1,2,3]}$ Program Studi Sastra Jepang, Fakultas Ilmu Budaya, Universitas Udayana \\ Denpasar, Bali-Indonesia \\ ${ }^{1}$ [nadyarizkianamadjid@gmail.com], ${ }^{2}$ [andry_anita@unud.ac.id], ${ }^{3}$ [indra_pradana@unud.ac.id]
}

\begin{abstract}
Abstrak
Penelitian ini membahas mengenai penerjemahan kalimat imperatif yang terdapat pada sebuah karya sastra berupa novel. Secara umum, penggunaan kalimat imperatif ditandai dengan adanya makna perintah maupun larangan. Namun, terdapat perbedaan antara jenis kalimat imperatif dalam satu bahasa dengan bahasa lainnya. Tujuan dari penelitian ini ialah untuk mengetahui jenis-jenis teknik dan metode penerjemahan yang digunakan dalam menerjemahkan kalimat imperatif dari bahasa Jepang ke dalam bahasa Indonesia. Data dianalisis melalui dua tahap, yaitu pertama mengkategorikan teknik penerjemahan yang digunakan berdasarkan teori teknik penerjemahan menurut Molina dan Albir (2002) dan kedua menentukan metode penerjemahan dengan menggunakan teori metode penerjemahan menurut Newmark (1988). Berdasarkan hasil analisis, ditemukan delapan jenis teknik penerjemahan, yaitu 1) teknik adaptasi; 2) teknik penambahan; 3) teknik padanan lazim; 4) teknik generalisasi; 5) teknik kompresi linguistik; 6) teknik harfiah; 7) teknik modulasi; dan 8) teknik reduksi. Selanjutnya ditemukan metode penerjemahan yang diklasifikasikan berdasarkan orientasi pada bahasa sumber dan bahasa sasaran. Metode penerjemahan yang berorientasi pada bahasa sumber terdiri atas dua metode penerjemahan, yaitu metode penerjemahan semantis dan metode penerjemahan harfiah. Sementara metode penerjemahan yang berorientasi pada bahasa sasaran terdiri atas tiga metode penerjemahan, yaitu metode penerjemahan bebas, metode penerjemahan idiomatik, dan metode penerjemahan komunikatif. Hasil dari penelitian ini menunjukkan bahwa metode penerjemahan yang paling dominan digunakan adalah metode penerjemahan bebas sehingga penerjemahan kalimat imperatif yang diterapkan dalam novel Girls in The Dark oleh Andry Setiawan cenderung berorientasi pada bahasa sasaran.
\end{abstract}

Kata kunci : Kalimat Imperatif; Teknik Penerjemahan; Metode Penerjemahan

\begin{abstract}
This study discusses the translation of imperative sentences contained in a literary work in the form of a novel. In general, the use of imperative sentences is characterized by the meaning of orders and prohibitions. However, there are differences between the imperative sentences of one language and another. Methods of data analysis are using translational equivalent method and glossing technique. The data were analyzed in two stages. First, categorizing the translation techniques used based on the theory of translation techniques according to Molina and Albir (20002), and second, determining the translation method using the theory of the translation method according to Newmark (1988). Based on the analysis, there were eight types of translation techniques found, namely 1) adaptation techniques; 2) amplification techniques; 3) established equivalent techniques; 4) generalization techniques; 5) linguistic compression techniques; 6) literal translation techniques; 7) modulation techniques; and 8) reduction techniques. Furthermore, translation method classified based on the orientation of the source language and target language is found. The translation method which is oriented to the source language consists of two translation methods, namely the semantic translation method and the literal translation method. Meanwhile, the translation method which
\end{abstract}


is oriented towards the target language consists of three translation methods, namely the free translation method, the idiomatic translation method, and the communicative translation method. The results of this study indicate the translation method that is most widely used in this research is free translation method so that the translation of the imperative sentences applied in translating the novel Girls in the Dark by Andry Setiawan tends to be oriented towards the target language.

Keywords : Imperative Sentence; Translation Technique; Translation Method

\section{Pendahuluan}

Pada era modern, perkembangan dari berbagai aspek kehidupan manusia seperti tingkah laku, pola pikir, bahkan penggunaan bahasa sehari-hari pun menjadi beraneka ragam. Salah satu penyebab terjadinya keberagaman budaya di negara Indonesia, yaitu dikarenakan masyarakat Indonesia menerima budaya dari luar atau budaya asing dengan baik, bahkan menjadikan budaya tersebut populer di sekitar lingkup pergaulan mereka. Demikian juga yang terjadi pada budaya Jepang di Indonesia. Minat masyarakat Indonesia akan budaya Jepang berkembang setelah masuknya tren musik, animasi, komik, dan novel. Akan tetapi, penggunaan bahasa asli yang masih digunakan dalam penyampaian informasi oleh negara asal dari budaya tersebut, seringkali menjadi penghambat bagi masyarakat Indonesia untuk memahami lebih dalam konteks yang dimaksud. Oleh karena itu, agar mempermudah komunikasi diperlukan adanya proses penerjemahan.

Penerjemahan adalah suatu kegiatan yang bertujuan untuk mengganti bentuk bahasa sumber $(\mathrm{BSu})$ menjadi bahasa sasaran $(\mathrm{BSa})$ dengan prioritas menyesuaikan unsur yang disampaikan dalam teks sumber (TSu). Hal ini dapat diartikan juga, penerjemahan merupakan bentuk usaha untuk menyampaikan arti pesan yang terkandung dalam suatu teks sumber (TSu) ke dalam teks sasaran (TSa) secara proporsional (Newmark, 1988: 5). Seorang penerjemah dalam melakukan kegiatan penerjemahan, tidak cukup hanya mampu memilih kata yang sepadan saja namun, perlu adanya pemahaman dan pengetahuan terhadap ilmu bahasa (linguistik) yang mempunyai peranan penting dalam proses penerjemahan. Salah satu kajian yang tergolong unik untuk diperbincangkan adalah kalimat perintah atau kalimat imperatif, karena mengandung bermacam-macam makna serta memerlukan ketelitian dalam memahaminya. 
Kalimat imperatif adalah kalimat yang menyatakan perintah atau suruhan kepada seseorang dengan harapan agar lawan bicara tersebut mampu melakukan sesuatu yang diungkapkan oleh pembicara. Kalimat imperatif terdiri dari enam golongan, yaitu kalimat perintah, larangan, perintah halus, permohonan, pembiaran dan ajakan. Contohnya, "Jangan duduki bantal ini". Kalimat imperatif tersebut masuk dalam kalimat imperatif larangan, karena pembicara mengatakan hal ini dengan maksud melarang lawan bicara agar tidak melakukan sesuatu yang diperintahkan, yaitu tidak menduduki bantal (Alwi, dkk, 2003:353-362).

Kalimat imperatif dalam tiap bahasa belum pasti memiliki penjelasan yang sama, seperti kalimat imperatif dalam bahasa Indonesia dengan kalimat imperatif dalam bahasa Jepang. Kalimat imperatif dalam bahasa Jepang dikenal terdapatnya pemakaian bahasa bersumber pada gender, ialah antara laki- laki dan perempuan. Seperti salah satu contoh kalimat imperatif berikut ini yang umumnya digunakan oleh laki-laki ditandai dengan pola てくれ ( te kure), yakni 早く帰ってきてくれ (Hayaku kaette kite kure) yang berarti 'cepat pulang!'. Kalimat ini sering digunakan oleh laki-laki karena memiliki kesan kurang sopan dan termasuk dalam ungkapan yang kasar (Iori, 2000:149). Perkembangan ilmu linguistik yang terjadi atas dasar keberagaman bahasa dalam setiap negara tentu berdampak pada kegiatan penerjemahan. Maka dari itu, penerjemah perlu menggunakan teknik dan metode penerjemahan dalam membantu kegiatan penerjemahan.

Penelitian ini mengkaji mengenai teknik dan metode penerjemahan kalimat imperatif dalam novel Girls in The Dark oleh Andry Setiawan menggunakan objek data berupa novel berbahasa Jepang yang berjudul Ankoku Joshi karya Akiyoshi Rikako yang isinya telah diterjemahkan menjadi bahasa Indonesia dengan judul novel Girls in The Dark oleh Andry Setiawan. Alasan pemilihan objek data berupa novel tersebut karena ditemukan beragam jenis kalimat imperatif seperti perintah, perintah halus, permohonan, ajakan, serta larangan.

Berdasarkan latar belakang yang telah disampaikan, kemudian dirumuskanlah permasalahan yang diteliti sebagai berikut:

a) Bagaimanakah teknik penerjemahan kalimat imperatif dalam novel Girls in The Dark oleh Andry Setiawan? 
b) Bagaimanakah metode penerjemahan kalimat imperatif dalam novel Girls in The Dark oleh Andry Setiawan?

Penelitian ini bertujuan untuk meningkatkan apresiasi terhadap karya sastra Jepang dalam bentuk novel, meningkatkan ketertarikan masyarakat terhadap penerjemahan, utamanya dalam penerjemahan novel, dan untuk menambah penelitian yang berkaitan dengan penerjemahan khususnya penerjemahan novel dari bahasa Jepang ke dalam bahasa Indonesia. Selain itu, tujuan khusus penelitian ini adalah untuk mengetahui teknik dan metode penerjemahan kalimat imperatif dalam novel Girls in The Dark oleh Andry Setiawan.

\section{Metode dan Teori}

\subsection{Metode Penelitian}

Pada bagian ini, dipaparkan metode serta teknik penelitian yang digunakan untuk mengumpulkan, membedah, serta penyampaian hasil analisis data. Untuk tahap pengumpulan data digunakan metode simak dan teknik catat. Selanjutnya, metode padan translasional dan teknik glossing merupakan metode dan teknik yang digunakan dalam proses analisis data.

\subsection{Teori}

Teori yang digunakan dalam penganalisisan adalah teori penerjemahan menurut Molina dan Albir (2002) yang bertugas untuk mengkategorikan teknik penerjemahan pada data. Selain itu, digunakan teori metode penerjemahan oleh Newmark (1988) untuk membedah penerjemahan kalimat imperatif pada data. Kemudian, hasil analisis diuraikan dengan menggunakan metode informal untuk memperoleh simpulan.

\section{Hasil dan Pembahasan}

Bagian ini menguraikan hasil analisis mengenai penggunaan teknik serta metode penerjemahan kalimat imperatif bahasa Jepang yang diterjemahkan menjadi bahasa Indonesia pada novel berjudul Girls in The Dark oleh Andry Setiawan (2016).

\subsection{Teknik Penerjemahan Adaptasi (Adaptation) dan Metode Penerjemahan Semantis (Semantic Translation) \\ TSu: 「待つ \\ "Matsu \\ Menunggu \\ 間、 \\ aida, ocha \\ selama \\ お茶 teh \\ に \\ $n i$ \\ DAT \\ しましょうか」 shimashouka" \\ melakukan-BAjk}


TSa: "Minum teh yuk sambil menunggu."

(Girls in The Dark, 2016:91)

Penerapan teknik penerjemahan adaptasi terlihat dari klausa "ocha $n i$ shimashouka" yang diterjemahkan menjadi "minum teh yuk" pada TSa. Proses adaptasi yang terlihat ialah kata "ocha" yang diterjemahkan menjadi "teh". Ocha dalam bahasa Jepang memiliki arti 'teh hijau' (Hadi, 2017). Klausa ocha ni shimasu memiliki makna 'melakukan kegiatan minum teh', namun teh tersebut berbeda dengan jenis teh yang umumnya dikonsumsi oleh masyarakat Indonesia. Teh yang dikonsumsi oleh masyarakat Indonesia merupakan jenis teh hitam sedangkan masyarakat Jepang meminum teh hijau. Penerapan interjeksi "yuk" pun digunakan karena terkesan lebih akrab dalam percakapan sehari-hari.

Penerapan metode semantis pada data (1) terlihat dari klausa "ocha $n i$ shimashouka" yang diterjemahkan menjadi "minum teh yuk". Terkait hal ini, penerjemah berusaha menyampaikan makna imperatif ajakan dengan mengganti istilah yang terkandung dalam TSu, yaitu "ocha" menjadi "teh" karena kata "teh" terkesan lebih akrab bagi budaya pembaca teks sasaran.

\subsection{Teknik Penerjemahan Penambahan (Amplification) dan Metode Penerjemahan Bebas (Free Translation)

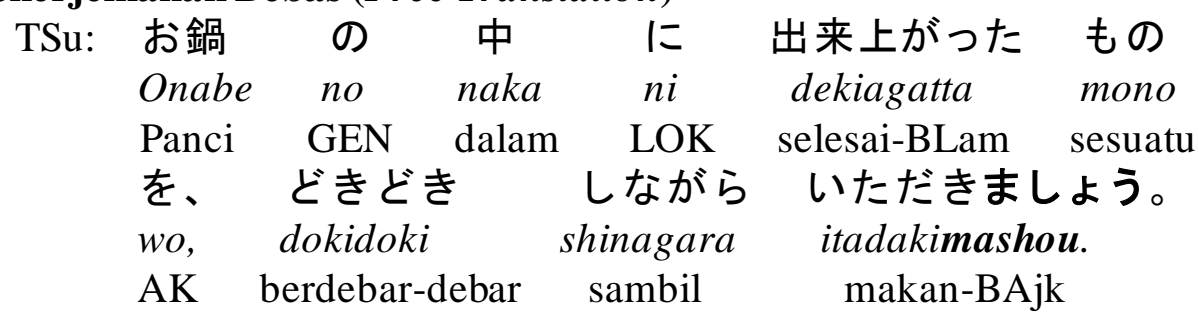

(暗黒女子、2013:12)

TSa: Mari kita nikmati hidangan ini dengan dada berdebar-debar.

(Girls in The Dark, 2016:12)

Penggunaan teknik penerjemahan penambahan terlihat pada penambahan kata "dada" dalam kata "dokidoki" yang jika diterjemahkan secara harfiah menjadi 'berdebar-debar'. Penambahan kata "dada" tersebut membantu pemahaman pembaca terhadap maksud dari penerjemah. Jika melihat penyesuaian pada tata bahasa BSa maka penerjemah lebih memilih kata "jantung" atau "hati" untuk mengganti kata "dada" 
sesuai dengan pengertian arti kata "dokidoki" yang terdapat dalam kamus, yaitu "jantung berdebar-debar' atau 'hati berdebar-debar' (Matsuura, 1994:149). Meskipun penambahan kata "dada" kurang berterima, namun jika dikaitkan dengan konteks yang meliputi kalimat di atas, makna ajakan dari kalimat imperatif pun tetap terlihat dengan adanya penambahan kata "dada" sebagai penjelas ajakan untuk menikmati hidangan dengan perasaan yang berdebar.

Metode penerjemahan bebas ialah metode penerjemahan yang berfokus pada isi dibandingkan bentuk dari TSu dan terdapat parafrasa yang lebih panjang atau pendek dari teks asli. Hal tersebut ditunjukkan dengan penambahan kata "dada" sebagai penjelas mengenai objek yang berdebar-debar.

\subsection{Teknik Penerjemahan Padanan Lazim (Established Equivalent) dan Metode Penerjemahan Idiomatik (Idiomatic Translation) \\ TSu:「気 に しないで いいよ」

"Ki ni shinaide ii yo" \\ Hati DAT melakukan-BPer baik SHU}

(暗黒女子、2013:182)

TSa: "Jangan diambil hati."

(Girls in The Dark, 2016:180)

Penerapan teknik penerjemahan padanan lazim terlihat dari kata " $k i$ " yang diterjemahkan menjadi kata "hati". Penerjemah memilih pilihan kata "hati" untuk menyesuaikan dengan budaya bahasa sasaran. Hal ini diperkuat dengan penjelasan sebuah artikel berjudul "Ki: more than a feeling" yang membahas mengenai arti dari kata “ki” dalam kalimat ki ni shinaide. Kata 気 (ki) memiliki banyak arti diantaranya, seperti 'pikiran', 'suasana hati', dan 'perasaan' (Tanahashi dan Hitomi, 2013). Berdasarkan beragam arti tersebut, dapat disimpulkan bahwa kata "ki" mengandung makna yang menggambarkan perasaan sehingga penerjemah memilih kata "hati" sebagai padanan dari TSu, karena kata tersebut cenderung pula digunakan dalam mengungkapkan hal yang berhubungan dengan perasaan.

Metode penerjemahan idiomatik terlihat dari keseluruhan hasil terjemahan, yaitu "jangan diambil hati" karena metode idiomatik mempunyai tujuan berusaha mengupayakan kesepadanan ungkapan penerjemahan ke dalam BSa. 


\subsection{Teknik Penerjemahan Generalisasi (Generalization) dan Metode Penerjemahan Komunikatif (Communicative Translation) \\ TSu:「なんでも お手 に とって Nandemo ote ni totte \\ Apa saja tangan DAT mengambil-BSbg \\ 読んでちょうたい」 yonde choudai. \\ membaca-BPmt}

(暗黒女子、2013:36)

TSa: Silakan mengambil dan membaca yang mana saja.

(Girls in The Dark, 2016:35)

Teknik penerjemahan generalisasi dapat dilihat pada penggunaan pola te choudai yang diterjemahkan menjadi kata "silakan". Ketentuan mengungkapkan ekspresi permohonan dalam bahasa Jepang memiliki tingkatan makna kesopanan, seperti bentuk te kudasai umumnya digunakan ketika seseorang menyatakan suatu permohonan secara sopan. Ada pula bentuk lebih sopan dibandingkan te kudasai yaitu bentuk te kudasaimasenka, sebab memiliki kesan paling sopan karena biasanya digunakan oleh bawahan kepada atasannya (Iori, 2000:149). Selain itu, ketatabahasaan bahasa Jepang juga memiliki perbedaan berdasarkan gender. Misalnya, bentuk te kure yang biasanya digunakan oleh laki-laki, sedangkan bentuk te choudai umumnya lebih sering digunakan oleh perempuan, anak-anak, atau teman dekat (Arino, 1998:256). Maka, penerjemah memilih kata "silakan" yang terkesan lebih umum dalam menerjemahkan bentuk te choudai yang lebih spesifik. Selain itu, dalam tata bahasa Indonesia tidak diterapkan secara khusus mengenai penggunaan kalimat yang menerangkan perbedaan gender.

Metode penerjemahan komunikatif terlihat dari pola te choudai yang diterjemahkan menjadi kata "silakan". Pada BSa tidak memiliki padanan untuk menerjemahkan pola te choudai yang memiliki makna spesifik, sehingga penerjemah menggunakan kata "silakan" sebagai kata penegas untuk mengungkapkan imperatif perintah halus sesuai dengan prinsip komunikasi karena hasil terjemahan tidak keluar konteks dari kalimat imperatif permohonan pada TSu.

\subsection{Teknik Penerjemahan Kompresi Linguistik (Linguistic Compression) dan Metode Penerjemahan Bebas (Free Translation) \\ $\mathrm{TSu}$ 「「いいじやない、是非 Ii janai, \\ zehi

$\begin{array}{ll}\text { いらして } & \text { よ」 } \\ \text { irashite } & \text { yo. }\end{array}$




\section{Baik-BNeg walau bagaimana juga datang-BPrmt SHU}

(暗黒女子、2013:77)

TSa: “Tidak apa-apa, kan. Datanglah.”

(Girls in The Dark, 2016:77)

Teknik penerjemahan kompresi linguistik terlihat dari adanya penciutan kalimat pada "zehi irashite yo" yang diterjemahkan hanya menjadi satu kata, yaitu "datanglah". Kata “zehi” memiliki arti 'walau bagaimana juga' atau 'bagaimanapun juga' (Matsuura, 1994:1212). Sementara, kata “irashite yo" memiliki arti “mohon datang'. Apabila kedua kata tersebut diterjemahkan secara harfiah maka penerjemahan akan menjadi kalimat yang tumpang-tindih karena antara kata "zehi" dan "irashite yo" sudah mengandung makna permohonan. Maka dari itu, penerjemah menciutkan kalimat dengan hanya menggunakan kata "datang” yang ditambahkan dengan partikel "-lah" sebagai bentuk menghaluskan nada dalam menerapkan kalimat imperatif (Alwi, dkk, 2003:308).

Metode penerjemahan bebas merupakan metode penerjemahan yang terlihat pada data (6). Dapat dilihat dari kalimat "zehi irashite yo" diterjemahkan dengan cara menciutkan kalimat menjadi satu kata, yakni "datanglah". Maka dari itu, hasil terjemahan mengalami parafrasa lebih pendek dari teks sumber.

\subsection{Teknik Penerjemahan Harfiah (Literal Translation) dan Metode Penerjemahan Harfiah (Literal Translation) \\ TSu：さきほどお配りした ウェルカム・ドリンク \\ Sakihodo okubarishita \\ Tadi membagikan-BLam \\ でも 召し上がり ながら、 \\ demo meshiagari nagara, \\ tapi makan sambil \\ お聞き ください ね。 \\ okiki kudasai ne \\ mendengar-BSpn tolong SHU \\ werukamu dorinku \\ minuman selamat dating \\ ゆったり と \\ yuttari to \\ santai PAR}

(暗黒女子、2013:7)

TSa: Silakan mendengarkan dengan santai sambil menikmati welcome drink yang sudah dibagikan tadi.

(Girls in The Dark, 2016:6)

Penerepan teknik harfiah terlihat dari hasil terjemahan yang sama antara TSu ke dalam TSa, hanya saja terdapat karakteristik dari bahasa Jepang, yaitu adanya bahasa tingkatan kesopanan yang ditandai dengan pola o kudasai. Pola ini merupakan bentuk 
hormat (keigo) dari te kudasai yang dinyatakan untuk meninggikan lawan bicara dengan maksud sebagai bentuk rasa hormat pembicara kepada lawan bicara (Iori, 2000: 150). Berkaitan dengan hal ini, dalam bahasa Indonesia mengenal istilah honorifik, yaitu suatu bentuk lingual yang digunakan untuk menyatakan rasa hormat ketika menyapa lawan bicara. Penggunaan kata honorifik terlihat dengan adanya kata sapaan seperti, Anda, Saudara, Pak, atau Beliau (Kridalaksana, 2008:85). Meskipun kata honorifik tidak terlihat dalam hasil terjemahan, pembaca sasaran tetap dapat memahami maksud penerjemah karena hasil terjemahan tidak mengurangi makna yang tampak pada kalimat imperatif permohonan pada TSu. Dengan demikian, kata "okikikudasai" yang diterjemahkan menjadi kata "silakan mendengarkan" termasuk dalam penerjemahan harfiah dengan jenis imperatif perintah halus.

Metode penerjemahan harfiah seimbang dengan teknik penerjemahan harfiah karena secara pengertian antara metode harfiah dan teknik harfiah memiliki kesamaan dalam penerapannya yaitu, mencari kesepadanan kata dengan cara pernerjemahan kata per kata dan proses penerjemahannya yang tidak mengubah makna meskipun mengikuti struktur BSa.

\subsection{Teknik Penerjemahan Modulasi (Modulation) dan Metode Penerjemahan Komunikatif (Communicative Translation)

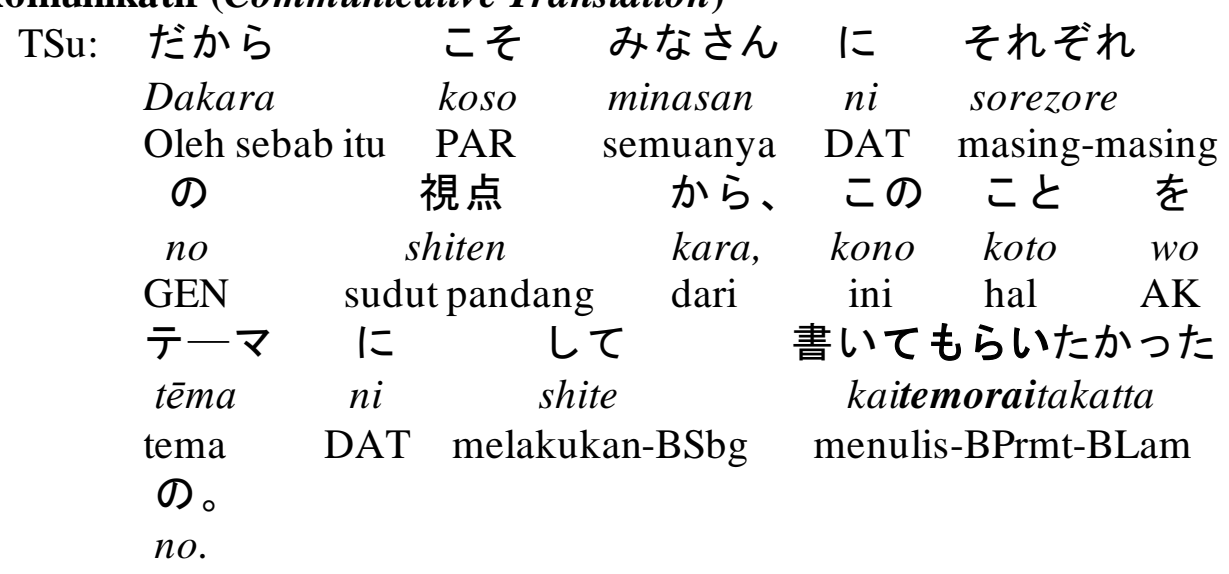

(暗黒女子、2013:20)

TSa: Karena itu saya meminta kalian menceritakan kejadian ini dari sudut pandang masing-masing.

(Girls in The Dark, 2016:20)

Penerapan teknik penerjemahan modulasi terlihat dari adanya perubahan kategori kognitif. Hal ini ditandai dengan kata "kaite" pada kalimat "kaitemoraitakatta" 
yang diterjemahkan menjadi "menceritakan". Kata "kaite" sejatinya memiliki makna 'menulis', namun penerjemah mengganti kata "menulis" menjadi kata "menceritakan". Hal ini dilakukan karena melihat situasi dalam cerita, yaitu pembicara mengucapkan kalimat tersebut pada sebuah pertemuan dengan sekelompok orang sebagai sebuah pengumuman. Penerjemah memilih pilihan kata "menceritakan" karena kata menceritakan bila dibandingkan dengan kata "menulis" lebih sesuai dalam konteks berbicara.

Metode penerjemahan komunikatif digunakan untuk menganalisis data di atas, yakni ditunjukkan dengan kalimat "kaitemoraitakatta" yang diterjemahkan menjadi "meminta kalian menceritakan". Meskipun mengubah penafsiran penerjemah berusaha menyampaikan makna kontekstual, sehingga pembaca dapat menerima dan mudah memahami maksud dari tujuan penerjemah.

\subsection{Teknik Penerjemahan Reduksi (Reduction) dan Metode Penerjemahan Bebas (Free Translation) \\ $\mathrm{TSu}$ :「車 \\ "Kuruma ni \\ Mobil \\ I \\ DAT \\ 乗りなさい」 \\ norinasai." \\ naik-BPer}

(暗黒女子、2013:260)

TSa: "Naik."

(Girls in The Dark, 2016:255)

Penerapan teknik penerjemahan reduksi terlihat dari adanya pemendekan atau pemadatan informasi dari TSu ke dalam TSa. Pada TSu, terdapat kalimat "kuruma ni norinasai" yang jika diterjemahkan menjadi "silakan naik ke mobil", namun pada TSa kalimat tersebut hanya diterjemahkan menjadi "naik". Hal ini dilakukan karena konteks percakapan yang terlihat jelas terjadi pada waktu usai sekolah, ketika pembicara yang berada di dalam mobil menyuruh lawan bicara yang saat itu sedang berjalan melewati gerbang sekolah agar naik ke dalam mobil. Dengan demikian, hilangnya informasi keberadaan mobil tidak mengurangi maksud yang terdapat dalam cerita.

Penerapan metode penerjemahan bebas terlihat karena berkurangnya jumlah kata yang terdapat pada TSu ke dalam hasil terjemahan yang dapat dilihat berdasarkan kalimat "kuruma ni norinasai" diterjemahkan menjadi "naik" pada TSa. 


\section{Simpulan}

Berdasarkan hasil uraian analisis, terdapat tiga hal yang disimpulkan pada penelitian teknik dan metode penerjemahan kalimat imperatif yang diterapkan dalam novel Girls in The Dark oleh Andry Setiawan. Pertama, ditemukan delapan jenis teknik penerjemahan yang dicetuskan oleh Molina dan Albir (2000), yaitu satu data teknik adaptasi, tiga data teknik penambahan, satu data teknik padanan lazim, satu data teknik generalisasi, dua data teknik kompresi linguistik, empat data teknik harfiah, dua data teknik modulasi, dan satu data teknik reduksi. Kedua, pada penerapan metode penerjemahan, ditemukan sebanyak lima jenis metode yang dikemukakan oleh Newmark (1988). Metode penerjemahan yang berorientasi pada BSu, ditemukan sebanyak dua jenis metode penerjemahan, yaitu satu data dengan metode semantis dan empat data dengan metode harfiah. Sedangkan, metode penerjemahan yang berorientasi pada BSa, ditemukan sebanyak tiga jenis metode penerjemahan, yaitu enam data dengan metode bebas, satu data dengan metode idiomatik, dan dua data dengan metode komunikatif.

Pada analisis teknik dan metode penerjemahan diketahui pula bahwa terdapat perbedaan mengenai penggunaan kalimat imperatif pada bahasa Jepang dan bahasa Indonesia. Hal itu berupa penggunaan kategori imperatif, yakni pada bahasa Jepang terdapat penggolongan tingkatan kesopanan, seperti $\sim$ te kudasaimasenka, te kudasai, hingga penggunaan bahasa berdasarkan gender, seperti pola te kure yang biasanya digunakan oleh laki-laki dan pola te choudai yang biasanya digunakan oleh perempuan atau anak-anak. Selain itu, terdapat penggunaan imperatif bahasa Jepang golongan permohonan yang memiliki padanan dengan imperatif perintah halus dalam bahasa Indonesia, seperti pola te kudasai dan te choudai yang diterjemahkan menjadi kata "silakan". Terakhir, ditemukan pola untuk menerangkan rasa hormat (keigo) dalam bahasa Jepang yang memiliki padanan dengan istilah honorifik dalam bahasa Indonesia.

Berdasarkan hal ini, penerjemahan kalimat imperatif yang diterapkan dalam novel Girls in The Dark oleh Andry Setiawan menggunakan metode penerjemahan bebas yang paling dominan sehingga dapat dikatakan penerjemahannya cenderung berorientasi pada bahasa sasaran. Penelitian selanjutnya diharapkan dapat melakukan penelitian dengan golongan imperatif lain, yakni jenis pembiaran dan menambahkan 
bahan analisis serta mengambil fokus pada perubahan penerjemahan, seperti teori analisis komponen makna untuk mencari pergeseran makna penerjemhan.

\section{Daftar Pustaka}

Alwi, Hasan dkk. 2003. Tata Bahasa Baku Bahasa Indonesia Edisi Ketiga. Jakarta: Balai Pustaka.

Arino, Sagawa. 1998. Nihongo Bunkei Jiten. Tokyo: Kuroshio Shuppan.

Hadi, Irene. 2017. Grid.id, 16 agustus 2017 - 'Suka Minum Matcha dan Ocha? Tahu Nggak Bedanya Apa?'. (Diakses 17 Desember 2020 pada https://www.grid.id/amp/04140729/suka-minum-matcha-dan-ocha-tahu-nggakbedanya-apa?page=all)

Iori, Isao. 2000. Nihongo Bunpou Hand Book. Japan: Corporation.

Kridalaksana, Harimurti. 2008. Kamus linguistik edisi ke-4. Jakarta: Gramedia.

Molina, Lucia and Amparo Hurtado Albir. 2002. Translation Techniques Revisited: A Dinamic and Fuctionalist Approach. Barselona: Universitas Autònoma de Barcelona.

Matsuura, Kenji. 2014. Kamus Bahasa Jepang-Indonesia. Jakarta: Gramedia Pustaka Utama.

Moriya, Shinaki. 1990. Gendai Gairaigo Jiten. Tokyo: Sanseido.

Newmark, Peter. 1988. A Textbook of Translation. UK: Prentice Hall.

Rikako, Akiyoshi. 2013. Ankoku Joshi. Tokyo: Futabasha.

Rikako, Akiyoshi. 2016. Girls in The Dark (Ankoku Joshi). Jakarta: Penerbit Haru.

Tanahashi, Akemi dan Tashiro, Hitomi. 2013. The Japan Times Life, 06 Oktober 2013 'Ki: more than a feeling'. https://www.japantimes.co.jp/life/2013/10/06/language/ ki-more-than-a-feeling/\#.XvCihGgzbIW (Diunduh 5 April 2019) 